Revista Iberoamericana, Vol. LXXIV, Núm. 222, Enero-Marzo 2008, 1-

\title{
CRÍTICA CINEMATOGRÁFICA Y FICCIÓN EN HORACIO QUIROGA
}

\author{
POR \\ Miriam V. GÁrate \\ Universidade Estadual de Campinas-Brasil
}

A MANERA DE SINOPSIS INTRODUCTORIA

El sostenido interés de Horacio Quiroga por el cine ha quedado registrado tanto en las numerosas notas, reseñas y breves ensayos de su autoría dados a conocer en la prensa periódica, como en un reducido pero significativo conjunto de ficciones constituido por cuatro relatos: "El espectro” (1921), "Miss Dorothy Phillips, mi esposa” (1922),"El puritano” (1926), "El vampiro” (1927). A lo largo de este trabajo, pretendo establecer algunos puntos de articulación, eventuales continuidades o imbricaciones entre ambas esferas de actuación -la periodística cinematográfica y la estrictamente cuentística-, así como orientar la reflexión, en un segundo momento, hacia el ámbito de las relaciones instituidas entre dispositivos ópticos, imaginario e imaginación literaria en dicho corpus. ${ }^{1}$ Para concluir, pretendo realizar una breve consideración acerca de la posibilidad de vincular la lógica deseante legible en esas ficciones a una categoría freudiana, la de pulsión de repetición y su correlato indisociable, la pulsión de muerte.

\section{I}

Comienzo citando un artículo en el que la crítica mordaz a la postura de los intelectuales ante el cine revela por contraste la de su autor. Afirma Quiroga en ese ensayo de 1922, publicado en el número 227 de la revista Atlántida:

Los intelectuales son gente que por lo común desprecian el cine. Suelen conocer de memoria, y ya desde enero, el elenco y programa de las compañías teatrales de primero y séptimo orden. Pero del cine no hablan jamás...

No es el caso averiguar si no se cumple con los intelectuales respecto del cine el conocido aforismo de estética por el cual todos los wagnerianos exclusivos silban sin cesar trozos de Verdi. Acaso el intelectual cultive furtivamente los solitarios cines de su barrio; pero no confesará jamás su debilidad por un espectáculo del que su cocinera gusta tanto como él, y el chico de la cocinera tanto como ambos juntos. Manantial democrático de arte,

\footnotetext{
${ }^{1}$ Con respecto a las relaciones técnica/ficción en la Argentina de comienzos del siglo xx, el estudio pionero de Beatriz Sarlo La imaginación técnica (1992), constituye un marco fundamental. Véase en especial el capítulo consagrado a "Horacio Quiroga y la hipótesis técnico-científica”.
} 
como se ve, y que a ejemplo de las canciones populares, da de beber a chicos, medianos, y hombres de vieja barba como Tolstoi.

Pero el intelectual suele ser un poquito advenedizo en cuestiones de arte. Una nueva escuela, un nuevo rumbo, una nueva tontería pasatista, momentista o futurista, está mucho más cerca de seducirle que desagradarle. Y como es de esperar, tanto más solicitado se siente a defender un ismo culaquiera, cuanto más irrita éste a la gente de humilde y pesado sentido común.

Cómo, pues, el intelectual no halló en el arte recién creado, atractivos que por su quijotería o snobismo hicieran de él su paladín? ("Los intelectuales y el cine” 286-7)²

No me dentendré en los argumentos de autoridad esgrimidos por Quiroga (que recurre a un ensayo de Clarté para legitimar las cualidades atribuidas al séptimo arte); ni en sus profecías (“el cine matará un día al teatro”, sostiene³); ni en su exaltación del cinematógrafo precisamente a causa de la popularidad del mismo y la necesidad de una colaboración activa por parte de los intelectuales que de ello resulta, en su opinión. Baste decir que tales consideraciones permitirían reflexionar sobre la actitud abierta, desprovista de prejuicios e inclusive en cierto sentido moderna de este no vanguardista y que valdría la pena cotejarla, por ejemplo, con el elitismo practicado por Martín Fierro, a fin de iluminar las relaciones diferenciales instauradas con los diversos linajes y lenguajes fílmicos en desarrollo durante esa época, así como la estrecha relación entre éstos y el tipo de público espectador. ${ }^{4}$

En lo que atañe a las potencialidades del dispositivo cinematográfico como máquina ilusionista que nutre y expande el imaginario humano mediante el expediente de la duplicación (casi) perfecta; como vehículo de identificación, de proyección de deseos, ${ }^{5}$ de

\footnotetext{
${ }^{2}$ Horacio Quiroga. Arte y lenguaje del cine. Las citas y número de página de los artículos referidos en el presente trabajo corresponden a dicha edición.

${ }^{3}$ Sobre el debate en torno a la trasposición de las convenciones teatrales a la práctica cinematográfica, un verdadero topoi en las polémicas del período, véanse, del mismo Quiroga, las tres notas publicadas en El Hogar, bajo el título común de “Teatro y cine” (números 934, 937 y 942, de 9/9/ 1927, 30/9/1927 y 4/11/1927 respectivamente, 177, 181, 185).

${ }^{4}$ Sobre la producción crítica y traducciones de tema cinematográfico publicadas en Martín Fierro véase mi ensayo "Martín Fierro ante el cine”. Para una visión amplia la crítica cinematográfica practicada por escritores en Latinoamérica, el trabajo de Jason Borge Avances de Hollywood, resulta insoslayable tanto por el valioso material compilado, como el análisis crítico del mismo.

${ }^{5}$ El efecto de "presencia visual” suscitado por la representación de personas o acontecimientos de hecho ausentes y no efectivos constituyó, como sostiene Ismail Xavier, el núcleo de la reflexión desarrollada por varios teóricos del cine. Para los fines del presente trabajo cabe destacar en especial el clásico de Edgard Morin, a cuyo respecto Xavier sostiene: "Edgard Morin hizo del proceso de identificación/proyección vivido por el espectador prácticamente el núcleo de su libro, Le cinéma ou l'homme imaginaire. En ese trabajo, que él mismo denomina “ensayo antropológico”, su interés se concentra en la discusión de un fenómeno que considera fundamental en la cultura del siglo xx: la metamorfosis del cinematógrafo en cine. El primero es simplemente la técnica de duplicación y proyección de la imagen en movimiento; el segundo es la constitución del mundo imaginario que se torna lugar de manifestación por excelencia de los deseos, sueños y mitos del hombre, gracias a la convergencia entre ciertas características de la imagen cinematográfica y determinadas estructuras mentales de base. Dentro de la literatura sobre cine, Morin corresponde a un ejemplo extremo de vinculación esencial entre el fenómeno de identificación y el propio cine como institución humana
} 
satisfacción de pulsiones arcaicas a través del concurso de una nueva tecnología; como espacio de con-fusión entre real/imaginario, presente/pasado, animado/inanimado, vivo/ muerto; como artífice de fantasmas (como lugar potencialmente privilegiado de emergencia de lo Unheimlich, por lo tanto), dos breves notas, de título y contenido semejante, resultan significativas: "Las cintas de ultratumba” (Caras y Caretas N 1132, 12/06/1920, 1921) y “Cine de ultratumba” (Atlántida, N 238, 26/10/1922,1922). En ambas se medita, en clave crítico-ensayística, precisamente sobre aquello mismo que ficcionalizará la producción literaria quiroguiana de tema cinematográfico.

Transcribo in extenso un par de párrafos pertenecientes a cada una ellas:

Cuando un hombre del mundo normal muere, su imagen permanece con el corazón de sus deudos y en algunas fotografías, tan muertas como él. Pero para el resto de la humanidad, la figura del difunto desaparece para siempre jamás. El cine salva a sus intérpretes de esta oscuridad saludable [...] En los últimos días nos ha sido dado rever El indultado. Sus dos protagonistas, Locwood y Stonell, están hoy muertos [...] La impresión que produce esta supervivencia a através del sudario, es ya bastante fuerte para los indiferentes. Para aquellas personas cuyo corazón estuvo fuertemente unido a Locwood o Stonell, la impresión cobra aspecto de alucinación torturante. ("Las cintas de ultratumba” 141-2)

Tres son las primeras figuras de Puro corazón: Lilian Gish, Clarine Seymour y Roberto Harron. Como a la luz del día, corren por la eléctrica pantalla, tan vivas, tan del momento, que por poco que extendieran los labios o las manos, alcanzarían a tocarnos. Viven realmente en ese instante. No son ellos fotografías de ropero o de vetusto album de familia: se ríen, se desvisten, se abrazan con la intensidad carnal de la vida misma, pues Clarine y Harron se abrazaron de verdad y prosiguen haciéndolo a despecho de la ilusión fotográfica. Y he aquí que Roberto Harron y Clarine Seymour, unidos en este instante mismo por un beso de amor, están muertos [...] A través de la caja, de la tierra, del más allá del tenebroso misterio, los amantes se encuentran noche a noche, vívidos y flagrantes ante la electricidad. (“Cine de ultratumba” 311-12)

Destaco ciertos motivos recurrentes en los que se pueden leer algunas ideas caras al pensamiento quiroguiano sobre lo cinematográfico, sus relaciones con otros dispositivos ópticos, sus facultades y límites en lo que respecta al efecto de presencia, de vida, de realidad (y al retorno indefectible de su contrario, desde luego). Frente al inmovilismo de la imagen fotográfica y a su componente fúnebre, decididamente privilegiados por la mirada del autor ("fotografías, tan muertas como él”, "fotografías de ropero o de vetusto album de familia”), el coeficiente específicamente cinético de lo fílmico (obra de un procedimiento en el que lo estático, lo discontinuo, el intervalo negro que separa los fotogramas juegan un papel esencial, como es sabido), comporta un suplemento de vida (de ilusión de vida), que se sobrepone, en el momento de la proyección, a la conciencia

y social. Para él, la identificación constituye “el alma del cine”. La participación afectiva debe ser considerada como "estado genético y como fundamento estructural del cine”, o sea, de aquello que es algo más que cinematógrafo (técnica de duplicación), que es materialización de lo que "la vida práctica no logra satisfacer” (16-7; traducción mía). Teniendo en vista la concepción quiroguiana del cine, legible tanto en sus artículos como en sus relatos de ficción, las nociones de identificación, de proyección y de participación afectiva resultan operativas y pertinentes para el análisis. 
de que también esas imágenes a pesar del movimiento no son menos fúnebres, por irremediablemente pretéritas, que las fijadas en una foto. ${ }^{6}$

A este efecto redoblado de presencia y de presente se yuxtapone algo cercano a lo que Max Milner (La fantasmagorie 45), al referirse al Castillo de los Cárpatos (1892), de Julio Verne, como paradojal antecedente de lo cinematográfico, denomina "principio de repetición a voluntad" y asocia, asimismo, a la principal cualidad del fetiche freudiano, resumible según él en la fórmula: “yo sé bien que no es verdad y sin embargo...”. Como el barón Rodolfo de Gortz, que se entrega cada noche a la delicia de escuchar la voz grabada de la Stilla, engañosamente resuscitada en el palco donde ha dispuesto una estatua de la soprano y una miríada de espejos; como el barón de Gortz, el espectador de cine que vuelve a la misma sala, que revé la misma película, que insiste en la misma imagen, "repite a voluntad" su deseo de repetición, así como se entrega al juego fetichista del "yo sé bien que no es verdad y sin embargo...” (volveré más adelante sobre esta cuestión). Y si la imagen proyectada, como sostiene Quiroga, es la de alguien que ha muerto; y si, además, el espectador/contemplador mantiene lazos afectivos fuertes con el sujeto/imagen presentificado en la pantalla, la delicia y el tormento parecen estar garantizados. También parece estarlo la posibilidad de ir más allá del límite (de la conciencia del límite infranqueable que marca indeleblemente esa escena en lo $\mathrm{real}^{7}$ ), por medio de la ficción literaria. Pensando en el cine y, ciertamente, entregándose a él, Quiroga descubre las

\footnotetext{
${ }^{6}$ En su ya clásico ensayo intitulado La chambre claire, ensayo que debe leerse en una solución de continuidad con al menos otros dos textos congéneres - “Ontologie de l’image photographique”, de André Bazin y el ya mencionado volumen de Morin-, Roland Barthes postula algunos rasgos definitorios de la fotografía: su fuerte lastre referencial, su capacidad de reproducir o repetir mecánicamente al infinito aquello que nunca más se repetirá existencialmente y, en consecuencia, el carácter ambiguo de la imagen resultante, su doble estatuto de presencia/ausencia. Así, a despecho del deseo de retener o de resucitar la imagen/instante fotografiados, que anima a dicha práctica; a despecho de eso que Bazin ha resumido en la feliz expresión “complejo de momia”, el tipo de experiencia suscitada es del orden de la pérdida, de lo espectral, del luto. Este aspecto resulta claro en la nomenclatura elegida por Barthes para tratar de la cuestión. Según él, la fotografía es objeto de tres prácticas -hacer, mirar, soportar-, de las cuales se derivan tres instancias: el operator o fotógrafo; el spectator que contempla o compulsa las imágenes reproducidas; aquél o aquello que es fotografiado, “especie de simulacro, de eidolon emitido por el objeto” que, sostiene Barthes, “de buen grado llamaría spectrum de la fotografía”, porque esa palabra mantiene, gracias a su raíz, cierta relación con el "espectáculo", dimensión a la cual suma "esa cosa un poco terrible que hay en toda fotografía: el retorno de lo muerto”. Dicho de otro modo aún: "la fotografía representa ese momento sutil en el que, a decir verdad, no soy ni un sujeto ni un objeto, sino un subjeto que se siente devenir objeto: vivo entonces una micro-experiencia de la muerte, del paréntesis, me torno verdaderamente espectro" (27). Por mucho que la imagen cinematográfica haya parecido torcer el curso de esa experiencia, gracias al factor movimiento y a la apertura en dirección al extracampo; por mucho que el cinematógrafo haya reforzado la ilusión de presencia y vida de sus espectros; por mucho que haya favorecido un ablandamiento de la conciencia de los límites (o quizá habría que decir, precisamente por eso), lo reprimido, eso que he llamado dimensión fúnebre, retornará en una escena parcialmente reconfigurada, como intentaré demostrar.

${ }^{7}$ Morin se ha referido a esa situación al tratar de lo que denomina "doble estado de conciencia” del espectador, estado "sorprendente por el que la ilusión de realidad resulta inseparable de la conciencia de que ella es realmente una ilusión, sin que dicha conciencia, no obstante, mate el sentimiento de realidad” (Le cinéma ou l'homme imaginaire, traducción mía, cursivas del autor).
} 
posibilidades dramático narrativas implícitas en esa otra escena. En estado seminal, las crónicas citadas contienen, pues, el núcleo de relatos tales como "El espectro” (1921), "El puritano" (1926), "El vampiro" (1927) y, en menor medida -o, mejor aún, ejecutado en otro "tono"-, de ese seudo guión irónico satírico, intitulado "Miss Dorothy Phillips, mi esposa” (1922). Pero, asimismo, la recíproca es verdadera, ya que de modo sintético idéntica reflexión comparece, puesta en la boca del narrador póstumo de "El Puritano":

Nunca hasta hoy la literatura ha sacado todo el partido posible de la tremenda situación entablada cuando un esposo, un hijo, una madre, tornan a ver en la pantalla, palpitante de vida, al ser querido que perdieron. (Quiroga, 764) ${ }^{8}$

Observación a la cual ese mismo narrador agrega de inmediato, dando una vuelta de tuerca que constituye el centro neurálgico de dicha narrativa, lo siguiente:

Pero jamás tampoco fue supuesta una tortura igual a la de una enamorada que ve por fin entregarse al hombre por quien ella se mató, y que no puede correr delirante a sus brazos, ni puede mirarlo, ni volverse si quiera a él, porque toda ella y su amor no son ya más que un espectro fotográfico! (764)

Quizá retorne más tarde a este cuento que relata la historia de una star apasionada y suicida, y del no menos apasionado pero inflexible puritano que le da título a la historia. Por el momento interesa tan sólo consignar la existencia de esos vasos comunicantes, de esas idas y vueltas, de ese tránsito de doble mano entre la producción crítico ensayística y la ficcional. En ese sentido, y puesto que resulta un elemento clave en la estética cinematográfica valorizada por Quiroga, que se proyectará sistemáticamente en su ficción a título de "recurso ilusionista”, de ilusión de realidad de la imagen, de ámbito de pasaje, circulación e interacción entre realidad e imagen, cabe citar también un trecho de la nota dedicada a "Griffith y las miradas expresivas" (Caras y Caretas, N 1114, 7/2/1920):

Cuéntase que en uno de sus viajes a París, Griffith tropezó en la Plaza de la Ópera con una joven cuya mirada dio de pleno en los ojos del director. Griffith sufrió una sacudida y quedó tan deslumbrado por la intensidad de expresión de aquella mirada, que corrió atrás de la joven. -¡Por favor, Mr. Griffith! -lo contuvieron sus acompañantes franceses - ¿qué pretende? -¿Lo que pretendo? - respondió el director. Pues contratarla en seguida. La expresión de sus ojos vale cien mil dólares en el primer filme [...] Esta es la anécdota. Pues bien: Griffith tenía una y mil veces razón... Lo que importa, a los efectos cinematográficos, es que la transeúnte fuera naturalmente expresiva: sin buscarlo y sin preparación previa... la fuerza primera e insustituible del actor del filme estriba en esa intención de la mirada, característica de las personas que hablan con los ojos. (66-7, cursivas del autor)

Dos rasgos indisociables -naturalidad y expresividad-, convergen en la producción de quien es considerado por Quiroga, aunque no sólo por él evidentemente, padre y

${ }^{8}$ Quiroga, Horacio. Todos los cuentos. Edición crítica, Napoleón Baccino Ponce de León y Jorge Laforgue. Colección Archivos, ALLCA XX, 1996. Las citas y número de página de los cuentos referidos en este trabajo corresponden a dicha edición. 
modelo de la mejor cinematografía de la época. De hecho, el pasaje transcripto se relaciona y dialoga con otro conjunto de notas, algunas ya mencionadas a pie de página, en las que se examina con perspicacia la distinción entre convenciones teatrales y fílmicas; distinción en pro de la cual aboga el escritor, que los norteamericanos y en especial las innovaciones técnicas introducidas por Griffith habrían consolidado, mientras que buena parte del cine europeo continuaría ignorando todavía, según él. Esta valorización de la cinematografía "yanqui” frente a la "latina”, así como algunas cualidades de esa diferencialidad, que parecen condensarse en la fórmula ya apuntada (naturalidad expresiva), y que rigen los movimientos, los gestos, pero muy especialmente la mirada de los actores reaparece en los relatos constituyendo ora una incrustación de lo crítico en el ámbito ficcional, ora una dramatización o representación de lo crítico en lo ficcional.

A título de ilustración de ambos aspectos aunados vale la pena mencionar las observaciones de ese repetido personaje llamado Guillermo Grant, protagonista de tres de los cuatro cuentos, quien relata de la siguiente manera la formidable mezcla de factura artificial y efecto verídico inherente a lo fílmico norteamericano:

A las diez en punto estaba en los talleres de la Universal [...] de modo que pude seguir hito a hito la impresión de varios cuadros.

No creo que haya muchas cosas más artificiales e incongruentes que las escenas de interior del filme.Y lo más sorprendente, desde luego, es que los actores lleguen a expresar con naturalidad una emoción cualquiera ante la comparsa de tipos plantados a un metro de sus ojos, observando su juego.

En el teatro, a quince o treinta metros del público, concibo muy bien que un actor, cuya novia del caso está junto a él en la escena, pueda expresar más o menos bien un amor fingido. Pero en el taller el escenario desaparece totalmente, cuando los cuadros son de detalle. Aquí el actor permanece quieto y solo mientras la máquina se va aproximando a su cara, hasta tocarla casi. Y el director le grita:

-Mire usted aquí... Ella se ha ido, entiende? Usted cree que la va a perder. Mírela con melancolía... Más! Eso no es melancolía!... Bueno, ahora, sí... La luz! Y mientras los focos inundan hasta enceguecerlo la cara del infeliz, él permanece mirando com aire de enamorado a una escoba o a un tramoyista, ante el rostro aburrido del director [...]

Admirables, de todos modos, estos seres que nos muestran luego en la totalidad del filme una caracterización sumamente fuerte a veces [...]

Y de paso sea dicho: todo el concepto latino del cine vale menos que un humilde filme yanqui, a diez centavos. Aquél pivota entero sobre la afectación, y en éste suele hallarse muy a menudo la divina condición que es primera en las obras de arte, como en las cartas de amor: la sinceridad, que es la verdad de expresión interna y externa. (Quiroga 449-50)

El tono lúdico jocoso que preside "Miss Dorothy Phillips, mi esposa”, permite que el narrador protagonista desnude el artificio y al mismo tiempo santifique la ilusión, que establezca una escala de valores en virtud de ese parámetro, que mida la eficacia de europeos y estadounidenses en el ejercicio de una nueva práctica que exige nuevos procedimientos. De un lado, pues, la gesticulación afectada; del otro, la expresión "sincera" de esos seres de luz y sombra que no solamente hablan con los ojos, sino que viven -nos convencen de que lo hacen- en y a través de ellos.

Habiendo consignado en líneas generales ese proceso de permanente migración de lo ensayístico a lo ficcional y viceversa; una vez determinados los principales leit motivs 
que son objeto de esa suerte de "contrabando" de lo fílmico a lo literario, me propongo focalizar a continuación algunas escenas de uno de los cuentos mencionados: "El espectro”. La lectura privilegiará el tratamiento dado al tópico de la mirada, catalizador e integrador de los restantes, punto de encuentro dramático entre lo imaginario y lo real, lo inanimado y lo animado, e integrará, en la medida de lo posible, aspectos homólogos presentes en los otros relatos.

Comienzo por una breve sinopsis de "El espectro", intriga triangular (a semejanza de "El puritano"), protagonizada por Guillermo Grant, escritor, y una pareja de estrellas hollywoodenses unidas en matrimonio: ella, Enid; el, Duncan Wyoming.

El cuento se organiza como un relato retrospectivo enunciado por el espectro de Grant, pero cabe aclarar que en el presente de la narración los tres personajes ya han muerto, por lo que la condición espectral resulta común a todos. En dicho presente, y en cuanto fantasmas, Grant y Enid asisten noche tras noche a los estrenos cinematográficos del Grand Spendid, a la espera de una película en especial, filmada por Wyoming poco antes de morir, que lleva el título (por cierto elocuente) de Más allá de lo que se ve. El motivo de ese rito cotidiano tiene que ver con el propósito de retornar a la vida, infiltrándose nuevamente en ella gracias a un artilugio.

Evocando la época en que conociera a quien entonces era esposa de su mejor amigo, Grant, dice:

De todas las mujeres que conocí en el mundo vivo, ninguna produjo en mí el efecto que Enid. Tenía ella entonces, cuando vivíamos en el mundo, la más divina belleza que la epopeya del cine ha lanzado a miles de leguas y expuesto a la mirada fija de los hombres. Sus ojos, sobre todo, fueron únicos. (Quiroga 542-3)

Verla, apasionarse, refrenar la pasión en nombre de la lealtad para con Wyoming, padecer durante dos meses el tormento de una inocente convivencia à trois en el Canadá, donde la pareja de actores se encuentra rodando un filme, son peripecias que preceden al súbito deceso del marido quien, agonizante, confía a Grant la misión de cuidar, como un "hermano", de su adorada Enid. La obediencia al mandato de amor fraterno, no obstante, durará poco, y luego de cuatro meses la reciente viuda y el fiel amigo Grant se arrojarán uno en brazos del otro. Cabe destacar que lo largo de este proceso, que se desarrolla en el “mundo real” de la ficción, varios enunciados vinculados a la mirada juegan un papel importante. Pero es sólo a partir de la “traición” (Enid se referirá a ese amor supuestamente adúltero como un "crimen”) que el cruce de miradas expresivas entre el fantasmático Wyoming, personaje de la pantalla, y la pareja Grant/Enid, tornados espectadores obsesivos, compulsivos, en un proceso que los conducirá a la muerte, pasará a constituir el elemento clave de la historia.

En efecto, transcurridos algunos meses se estrena una de las dos películas rodadas por Wyoming poco antes de morir: 
Una noche -estábamos en Nueva York- me enteré de que se pasaba por fin El páramo, una de las dos cintas de que he hablado, y cuyo estreno se esperaba con ansiedad. Yo también tenía el más vivo interés de verla y se lo propuse a Enid. ¿Por qué no? [...] Fuimos al Metropole, y desde la penumbra rojiza del palco vimos aparecer, enorme y con el rostro más blanco que a la hora de morir, a Duncan Wyoming. Sentí temblar bajo mi mano el brazo de Enid. (546)

"Curiosamente”, el conjuro ensayado para vencer el pavor y olvidar consiste en retornar nuevamente al cine, en enfrentarse una y otra vez con esa presencia fantasmática pero "palpitante de vida". Y será precisamente en dicha circunstancia que, en una suerte de ficción crítica intercalada en el interior del cuento, Grant ofrecerá un pequeño resumen del filme al lector (espejo parcial de la historia en curso, vivida fuera de la pantalla), así como estimará la calidad del desempeño del fallecido amigo:

Una y otra noche, siempre atentos a los personajes, asistimos al éxito de El páramo. La actuación de Wyoming era sobresaliente... La situación central constituíala una escena en que Wyoming, herido en la lucha con un hombre, tiene bruscamente la revelación del amor de su mujer a ese hombre, a quien él acaba de matar por motivos apartes de este amor. Wyoming acababa de atarse un pañuelo a la frente. Y tendido en el diván, jadeando aún de fatiga, asistía a la desesperación de su mujer sobre el cadáver del amante.

Pocas veces la revelación del derrumbe, la desolación y el odio han subido al rostro humano com más violenta claridad que en esa circunstancia a los ojos de Wyoming. La dirección del filme había exprimido hasta la tortura aquel prodigio de expresión [...] Enid y yo, juntos e inmóviles en la oscuridad, admirábamos como nadie al muerto amigo, cuyas pestañas nos tocaban casi cuando Wyoming venía desde el fondo a llenar él solo la pantalla. Y al alejarse de nuevo a la escena del conjunto, la sala entera parecía estirarse en perspectiva. Y Enid y yo, con un ligero vértigo por ese juego, sentíamos aún el roce de los cabellos de Duncan que habían llegado a rozarnos. (547-8)

Innecesario insistir sobre el hecho de que los criterios valorativos coinciden con los de la nota sobre Griffith: el odio sube al rostro y en especial a los ojos de Wyoming, dando lugar a un prodigio de expresión; la expresividad, a su vez (y sobre todo el movimiento de cámara que dibuja la palabra, en una suerte de sucedáneo verbal de un doble travelling), suscita un efecto de realidad que se traduce como ilusión de contacto: ${ }^{9}$ las pestañas

\footnotetext{
${ }^{9}$ En el capítulo inicial de “La ventana del cine y la identificación”, Ismail Xavier se refiere a los dos procedimientos tradicionalmente considerados fundadores del arte cinematográfico: expresividad y montaje. En el primero, "se mantiene el registro continuo pero se le da movilidad a la cámara”; en el segundo, "se introduce la discontinuidad de registro”. En lo que respecta al primer procedimiento, Xavier afirma: "En el movimiento continuo la abertura de un nuevo campo de visión tiende a reforzar la característica básica del marco cinematográfico, conforme la tesis de Bazin: ser centrífugo. El movimiento de cámara es un dispositivo tremendamente reforzador de la tendencia a la expansión [...] y, como dice Burch, transforma el espacio "exterior a la pantalla” en espacio directamente enfocado (aprehendido) por la cámara” (15, traducción mía). La contaminación entre los espacios interno/externo que de ello resulta es recurrentemente dramatizada por Quiroga, recurso del cual el trecho citado constituye una ilustración.
} 
incorpóreas del actor tocan los cuerpos de la pareja sentada en las butacas; sus cabellos los rozan. Habiendo alcanzado este punto, la mirada se independiza y cobra vida tomando una nueva dirección distinta de la filmada, proceso que evoluciona y se intensifica hasta “tocar” el límite que separa (que ya no separa) lo proyectado de lo vivido, lo fantasmático de lo real:

¿Por qué continuábamos yendo al Metropole?... ¿Qué presagio nos arrastraba como a sonámbulos ante una acusación alucinante que no se dirigía a nosotros, puesto que los ojos de Wyoming estaban vueltos a otro lado? ¿Adónde miraban? No sé dónde, a un palco cualquiera de nuestra izquierda. Pero una noche noté, lo sentí en la raíz de los cabellos, que los ojos se estaban volviendo hacia nosotros” (548)

[...] noche a noche, palco tras palco, la mirada se iba volviendo cada vez más a nosotros [...] Mientras el Metropole ardía de luz, el mundo real de las leyes físicas se apoderaba de nosotros y respirábamos profundamente. Pero en la brusca cesación de la luz, que como un golpe sentíamos dolorosamente en los nervios, el drama espectral nos cogía otra vez.

A mil leguas de Nueva York, encajonado bajo tierra, estaba tendido Duncan Wyoming. Mas su sorpresa ante el frenético olvido de Enid, su ira y su venganza estaban vivas allí, encendiendo el rastro químico de Wyoming, moviéndose en sus ojos vivos, que acababan por fin de fijarse en los nuestros. [...]

Con lentitud de ira y los ojos clavados en nosotros, Wyoming se incorporaba del diván. Enid y yo lo vimos levantarse, avanzar hacia nosotros desde el fondo de la escena, llegar al monstruoso primer plano... Un fulgor deslumbrante nos cegó, a un tiempo que Enid lanzaba un grito. La cinta acababa de quemarse. (549)

Fiel a ciertas reglas básicas de lo fantástico, el relato propone hipótesis o consideraciones de cuño cientificista que buscan, sin lograrlo, explicar el fenómeno, así como procede por gradación: climax, distensión, recomienzo. ${ }^{10}$ Asimismo, y para continuar desarrollando un juego imaginativo según el cual el discurso proyecta formas correspondientes (no equiparables) a lo visual, podría afirmarse que toda la escena se construye a partir de un procedimiento del orden del campo/contracampo, que el lector "ve" alternativamente lo que sucede en la pantalla y en la sala, que salta del primer plano de los ojos airados de Wyoming a los de la apavorada de la pareja, que sigue el desplazamiento de las miradas hasta el punto/momento exacto del cruce, del encuentro, del desenlace trágico. ${ }^{11}$ En efecto, al día siguiente de haberse quemado la cinta los

${ }^{10}$ Sobre las convenciones y procedimientos del modo fantástico, además de los clásicos de Louis Vax, Tzvetan Todorov e Irenne Bessière, pueden consultarse, entre otros: Remo Ceserani (1999); Jean Faivre (1991); Jean Finne (1980); Charles Grivel (1992); Mary Erdal Jordan (1998); Denis Mellier (2000).

11 Afirma Ismail Xavier: "Un caso fundamental de combinación entre cámara subjetiva y shot/ reaction shot es el del llamado campo/contracampo, procedimiento clave en un cine dramático construido dentro de los principios de la identificación. Su punto de aplicación máxima se da en la filmación de diálogos. Ora la cámara asume el punto de vista de uno, ora de otro de los interlocutores, proporcionando una imagen de la escena a través de la alternancia de puntos de vista diametralmente opuestos. Con este procedimiento el espectador es lanzado para dentro del espacio del diálogo. Él, al mismo tiempo, intercepta y se identifica con dos direcciones de miradas, en un efecto que se 
protagonistas retornan por última vez al Metropole - Enid, con las pupilas ya opacadas por "las tinieblas del más allá”; Grant, “con un revólver en el bolsillo”:

Yo fui toda la vida dueño de mí. Lo fui hasta la noche anterior, cuando contra toda justicia un frío espectro que desempeñaba su función fotográfica de todos los días crió dedos estranguladores para dirigirse a un palco a terminar el filme.

Como en la noche anterior, nadie notaba en la pantalla algo anormal [...] Pero Enid... tenía la cara vuelta a la luz, pronta para gritar... Cuando Wyoming se incorporó por fin.

Yo lo vi adelantarse, crecer, llegar al borde mismo de la pantalla, sin apartar la mirada de la mía. Lo vi desprenderse, venir hacia nosotros en el haz de luz, venir en el aire por sobre las cabezas de la platea, alzándose, llegar hasta nosotros con la cabeza vendada. Lo vi extender las zarpas de sus dedos... e hice fuego.

No puedo decir qué pasó en el primer instante. Pero en pos de los primeros minutos de confusión y de humo, me vi con el cuerpo colgado fuera del antepecho, muerto.

Desde el instante en que Wyoming se había incorporado del diván, dirigí el cañón del revólver a su cabeza. Lo recuerdo con toda nitidez. Y era yo quien había recibido la bala en la sien. (550-1)

Subrayo lo evidente, esto es, la repetición obsesiva de verbos de visión: yo lo vi adelantarse, lo vi desprenderse, venir, lo vi extender las zarpas de sus dedos e inesperadamente me vi con el cuerpo colgado, me vi muerto. Proyección de sí en el otro y desdoblamiento de sí en otro se conjugan en el interior de un proceso que aduna exceso y falta. Por un lado, el de la "falta", se verifica el ofuscamiento o borradura del "principio de realidad"; por el otro, y como reverso indisociable del mismo fenómeno, la debilitación de lo real revierte en beneficio de la (excesiva) "realidad del fantasma". Ciego en relación a la barrera que distingue la otra escena de ésta, Grant no es más dueño de sí, es víctima de su alucinación, no ve la línea casi invisible y no obstante fundamental que nos impide, generalmente, entregarnos de cuerpo y alma a nuestros delirios. ${ }^{12}$

Muertos los protagonistas, se cierra provisoriamente la historia ("Tres días después Enid quedaba a su vez desalojada de este mundo. Y aquí concluye nuestro idilio”), para reabrirse una vez más:

Pero no ha concluido aún. No son suficientes un tiro y un espectro para desvanecer un amor como el nuestro.

multiplica por su percepción privilegiada de las dos series de reacciones expresivas en la fisonomía y los gestos de los personajes” (26, traducción mía). Aunque la escena textual no se organice bajo la forma de un diálogo, considero que el conjunto de consideraciones realizadas por Xavier resulta aplicable al texto.

${ }_{12}$ Ofuscamiento análogo del principio de realidad y de avance correlativo de la dimensión fantasmática alucinatoria se verifica en "Cine Prado", de Helena Poniatowska (De noche vienes; 1979), relato en el que un admirador enajenado termina por apuñalar la imagen de Françoise Arnould proyectada en la pantalla. La inscripción de dicho proceso en un marco temático semejante (el del universo cinematográfico, sus frecuentadores compulsivos -en este caso, también el narrador protagonista-, sus estrellas, las demenciales pasiones que éstas desencadenan, etc.), da forma a una peripecia y a un desenlace parcialmente distintos que, no obstante, valdría la pena examinar desde una perspectiva comparada. 
Más allá de la muerte, de la vida y sus rencores, Enid y yo nos hemos encontrado. Invisibles dentro del mundo vivo, Enid y yo estamos siempre juntos, esperando el anuncio de otro estreno cinematográfico.

[...] No hemos vuelto a ver más El páramo [...] Ahora nuestra esperanza está puesta en Más allá de lo que se ve. Desde hace siete años la empresa filmadora anuncia su estreno, y hace siete años que Enid y yo esperamos. Duncan es su protagonista... En las presentes circunstancias Duncan puede cometer un error que nos permita entrar de nuevo en el mundo visible, del mismo modo que nuestras personas vivas, hace siete años, le permitieron animar la helada lámina de su filme [...]

Al más leve movimiento que efectúe el actor, apenas se desprenda de la pantalla, Enid y yo nos deslizaremos como por una fisura en el tenebroso corredor [...]. Dentro de un mes o de un año, ello llegará. Sólo nos inquieta la posibilidad de que Más allá de lo que se ve estrene bajo otro nombre, como es de costumbre en esta ciudad. Para evitarlo, no perdemos un estreno. (551-2)

Cinéfilos espectrales (pero ¿acaso no es una tautología? ¿todo cinéfilo, “muerto” o vivo, no es una suerte de espectro?), Grant y Enid no pierden un estreno, en la expectativa de ver (otra vez, pero en sentido inverso) Más allá de lo que se ve. Desde luego que algo no muy diferente hacemos todos nosotros, cada vez que nos internamos en la sala oscura.

III

Para concluir, quisiera realizar algunas consideraciones acerca de esa pulsión común, que anima de manera ostensiva las acciones de los personajes tanto de "El espectro", cuanto de "El puritano", y que pone en juego una escena situada precisamente más allá de lo que se ve, no obstante se materialice a través del tópico de la mirada: la pulsión de repetición. De hecho ¿qué fuerza arrastra a Guillermo Grant y Enid, en vida, a frecuentar noche tras noche el Metropole y departir con el fantasma muerto/vivo de Wyoming? ¿Por qué el puritano, habiendo logrado resistir al poder de seducción de la star viva termina abandonándose reiteradamente al espectro de la star muerta/viva, proyectado en la pantalla? ¿Y por qué, en ambos casos, el desenlace de esa reiterada ceremonia es la muerte de los que se han dejado fascinar, tal vez creyendo hacer lo contrario, por el poder alucinatorio de la imagen?

Dos fuerzas de signo "distinto" parecen presidir tales ceremonias y disputarse la existencia de sus participantes: por un lado -y Grant lo explicita en determinado momento-, se vuelve al cine, se retorna una y otra vez, para poder “olvidar”. Freudianamente, cabría afirmar que la repetición se vincula en este caso al intento de "elaborar" (retrospectivamente) el trauma, de forjar un mecanismo de defensa denominado "ansiedad"; que se repite y revive la misma escena para domesticar el "susto”, pues, familiariarizándose con dicha situación, el factor sorpresa, lo inesperado, lo violento de la experiencia traumática, va mitigándose poco a poco y deja de ser (omni)presente (Freud 1916). En primera instancia, pues, en estos relatos se vuelve una y otra vez a ver la misma película para matar al muerto de una vez por todas (se trate de Duncan Wyoming o de Ella, la star innominada de "El puritano"), para sepultarlo e, hipotéticamene, hacer prevalecer el derecho de los vivos. Concebida de esa forma, la repetición, el acto repetido, se subordina 
al principio del placer -en otras palabras, tiene por misión reducir el displacer suscitado por la irrupción del fantasma y restituir parcialmente el equilibrio-, bien como a la pulsión de vida. Por doloroso que pueda resultar, el acto repetido encontraría su función y su razón de ser en la elaboración del duelo. Se va, se revé, se asiste, se revisita ciertos lugares del pasado, se los (re)construye frecuentándolos a fin de convencerse de que pertenecen irremediablemente al pasado y de reinscribirlos/reescribirlos en el interior de una historia presente. Ese sería el papel desempeñado en la narrativa por esa suerte de sucedáneo terapéutico llamado cine, práctica no casualmente considerada por algunos estudiosos como un "psicoanálisis de los pobres” (Predal 1989).

La trama de los cuentos de Quiroga revelaría en su superficie esta dinámica. Grosso modo, la pareja Grant/Enid ve repetidamente (en vida) El páramo para elaborar su sentimiento de "culpa"; para conjurar el "crimen", como lo llama Enid, de un "adulterio" que no ha sido tal. Como los niños, y como los "buenos neuróticos” que en mayor o menor medida somos todos, estos personajes confunden fantasía y realidad, son víctimas de aquello que caracteriza el pensamiento infantil y permanece como intenso resabio en el neurótico, a saber, la omnipotencia, mecanismo por el cual lo imaginado o deseado y lo ocurrido parecen "valer lo mismo" y ser, no pocas veces, uno consecuencia del otro. Poco importa no haber traicionado en acto a Wyoming, basta haberlo traicionado mentalmente; poco importa no haberlo matado, basta haber deseado en algún instante hacerlo desaparecer ("natural” por lo tanto que Wyoming "resucite” y clame venganza).

Nos encontramos así con una situación paradojal aunque, necesario es reconocerlo, bastante familiar: los personajes, cual pacientes en proceso de cura, visitan una y otra vez sus (propios) fantasmas para distinguir, discernir, diferenciar fantasía y realidad, pasado y presente, a fin de poder "vivir la vida". Ocurre que, lejos de distinguir, los personajes confunden cada vez más y más esos planos. Nada se elabora, nada se resuelve, nada se mitiga, nada (subjetivamente) se transforma, nada se distingue o discierne. Al contrario, los personajes se dejan arrastrar por el poder de ilusión de un fantasma que va cobrando cada vez más materialidad y que, en lugar de "ser muerto", "mata” a los protagonistas. A lo largo de ese camino, la hegemonía del principio del placer y de la pulsión de vida han cedido su lugar a una pulsión hipotéticamente antagónica, la pulsión de muerte. La repetición, en efecto, no ha servido para elaborar una diferencia en beneficio de la vida (entendida ella misma como diferencia, como diferir en el tiempo); ha acortado la distancia y adelgazado la distinción entre muertos y vivos, pasado y presente, alucinación y realidad, decidiendo la partida a favor del primero de los polos; ha hecho de la escena el reino de lo mismo.

La pregunta que fatalmente (freudianamente) se impone es: ¿en última instancia, no es esa la realidad última del deseo?, ¿no es esa la primera y última de las pulsiones? O bien, ¿el destino y dirección última de toda pulsión no es acaso la muerte, el retorno al supremo equilibrio de lo inorgánico? Si así fuera, las imágenes proyectadas en la pantalla no serían sino la proyección de los propios fantasmas (entendidos en su acepción más estrictamente psicoanalítica). También lo sería, desde luego, la literatura que les da forma. De hecho, resultaría bastante fácil reconducir esta constelación fantasmática a una biografía como la de Horacio Quiroga: padrastro suicida, suicida él mismo, "homicida” accidental de algunos seres queridos. Historias de amor, de locura y de muerte abundan, como sabemos, 
en sus ficciones. En ese sentido, los relatos de temática cinematográfica ponen a rodar lo mismo que los otros, ellos también se repiten (y nos repiten). No obstante, a la pulsión fúnebre que es la repetición, Quiroga supo oponerle, trabajándola, la fuerza de una imaginación extremamente fértil en variaciones, tonalidades, matices y, asimismo, afinada con los aspectos más significativos de la cultura de su tiempo. Un motivo, entre otros, de la vitalidad de sus fantasmas y del interés de su lectura, aún hoy.

\section{BiBLIOGRAFÍA}

Barthes, Roland. La chambre claire. París: Gallimard-Seuil, 1980.

Bazin, André. “Ontologie de l’image photographique”. Qu'est-ce que le cinéma? I. Ontologie et langage. París: Editions du Cerf, 1958.

Bessière, Irenne. Le récit fantastique. La poétique de l'incertaine. París: Larousse, 1974. Borge, Jason. Avances de Hollywood. Crítica cinematográfica en Latinoamérica, 19151945. Rosario: Beatriz Viterbo, 2005.

Brunetta, Gianni Piero. Nacimiento del relato cinematográfico. Madrid: Cátedra, 1993. Ceserani, Remo. Lo fantástico. Madrid: Visor, 1999.

Faivre, Jean, org. La littérature fantastique. Cahiers de l'Hermetisme. Colloque CerisyLa Salle. París: Albin Michel, 1991.

Freud, Sigmund. "Lo ominoso". De la historia de yba beyrisus ubfabtuk y otras obras (1917-1919). Obras, vol. XVII. Buenos Aires: Amorrotu, 1996.

“Más allá del principio del placer”. Psicología de las masas y análisis del yo y otras obras. Obras, vol. XVIII. Buenos Aires: Amorrortu, 1996.

Gárate, Miriam V. “Martín Fierro ante el cine”. Actas del V Congreso Internacional de Literatura Latinoamericana. México: Universidad Autónoma de México, 2005, en prensa.

Grivel, Charles. Fantastique-fiction. París: PUF, 1992.

Jordan, Mary Erdal. La narración fantástica. Frankfurt/Madrid: Vervuert/Iberoamericana, 1998.

Mellier, Denis. La littérature fantastique. París: Seuil, 2000.

Milner, Max. La fantasmagorie. París: PUF, 1982.

Morin, Edgard. Le cinéma ou l'homme imaginaire. París: Minuit, 1956.

Quiroga, Horacio. Arte y lenguaje del cine. Estudio preliminar de Carlos Dámaso Martínez. Gastón Gallo, comp. Buenos Aires: Losada, 1997.

Todos los cuentos. Edición crítica, Napoleón Baccino Ponce de León y Jorge Laforgue. Colección Archivos, ALLCA XX, 1996.

Predal, René. "Le film fantastique: psycanalyse du pauvre? Sigmun, King-Kong, Tarzon et les autres”. Cinémaction 50 (1989).

Sarlo, Beatriz. La imaginación técnica. Sueños de la cultura argentina. Buenos Aires: Nueva Visión, 1992.

Todorov, Tzvetan. Introduction à la littérature fantastique. París: Seuil, 1970.

Vax, Louis. La séduction de l'étrange. París: PUF, 1965.

Xavier, Ismail. O discurso cinematográfico. A opacidade e a tansparência. Río de Janeiro: Paz e Terra, 1984. 
